\title{
S. V. Vonsovskii: To the 100th Anniversary from the Birthday
}

DOI: $10.1134 / \mathrm{S} 0031918 X 10090012$

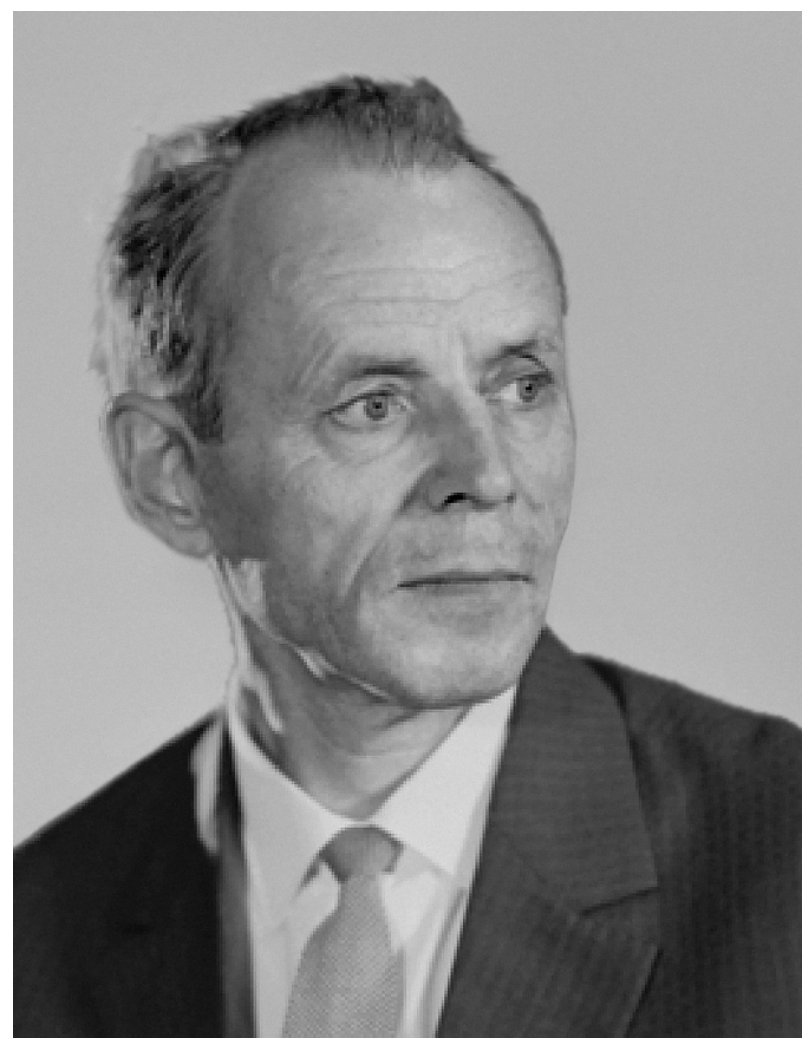

On September 2, 2010, we commemorate the hundredth anniversary from the birthday of our outstanding compatriot Academician Sergei Vasil'evich Vonsovskii (1910-1998).

The works of Sergei Vasil'evich in the field of the quantum solid state theory, many-electron theory of metals and semiconductors, theory of ferro- and antiferromagnetism, and superconductivity obtained the worldwide acknowledgment. The polar and $s d$-exchange models of metals he has developed are the base models in the quantum solid state theory and serve as a basis for studying physical properties of transition and rare-earth metals and their compounds.

The fate of Sergei Vasil'evich Vonsovskii is closely related to the Ural; he made a ponderable contribution to the organization of physical science in the Ural. After graduating from the Leningrad University in 1932, S.V. Vonsovskii worked in the Ural Physicotechnical Institute; since 1939, he headed the division of theoretical physics at the Institute of Metal Physics (IMP); then, he was Deputy Director of the IMP. For many years, he was in fact the scientific leader of the IMP and initiated many new directions of studies, such as low-temperature physics, semiconductors, X-ray diffraction spectroscopy, magnetic neutron diffractometry. In 1971-1985, he headed the Ural Scientific Center. Since 1947, he was a professor of the Ural University.

Sergei Vasil'evich was the permanent editor in chief (1955-1998) of the Fizika metallov $i$ metallovedenie (Physics of Metals and Metallography) journal created on his initiative.

The scientific and public activity of S.V. Vonsovskii has been highly evaluated. He was awarded with the Order of Lenin, Order of the Red Star, Order of the Red Banner of Labor; he is honored the title of Hero of Socialist Labor. Sergei Vasil'evich is a laureate of the State Prizes of the USSR, of the Vavilov medal, Demidov prize; he is a member of the German and Polish Academies of Sciences. S. V. Vonsovskii is an honorable citizen of Ekaterinburg; one of the streets of the city is called by his name. He was a deputy of the City Council (19551959) and of the Supreme Soviet of the Russian Soviet Federated Socialist Republic (1963-1971).

Editorial Board 